\title{
Perception of Healthcare Access and Utility of Telehealth Among Parkinson's Disease Patients
}

\author{
Dakota Peacock (D), Peter Baumeister, Alex Monaghan, Jodi Siever, \\ Joshua Yoneda, Daryl Wile
}

\begin{abstract}
Regional patient and physician density patterns pose problems to accessing care for people with Parkinson's disease, though telehealth may improve access. We surveyed and conducted a focus group for people with Parkinson's disease in Interior British Columbia regarding barriers to neurological care. Eighteen individuals completed the survey and seven parties joined the focus group. Perceived barriers include cost and difficulty of travel, wait times, and lack of specialized services outside large cities. $80 \%$ of participants (95\% CI 64-96) would likely use telehealth for follow-up neurologist appointments. This sample of people with Parkinson's disease reports willingness to use telehealth to reduce travel and improve access to specialty care.
\end{abstract}

RÉSUMÉ : Perceptions au sujet de l'accès aux soins de santé et de l'utilité de la télémédecine parmi des patients atteints de la maladie de Parkinson. À l'échelle d'une région, tant le nombre de patients que la densité médicale (physician density) posent des problèmes d'accès aux soins de santé pour les patients atteints de la maladie de Parkinson (MP), et ce, même s'il est possible que la télémédecine puisse apporter des améliorations. Nous nous sommes ainsi penchés sur les obstacles à l'obtention de soins neurologiques en organisant un groupe de discussion (focus group) avec des individus atteints de MP qui vivent dans l'intérieur de la Colombie-Britannique. Au total, 18 individus ont complété dans un premier temps notre sondage ; par la suite, 7 d'entre eux ont participé à notre groupe de discussion. Parmi les obstacles perçus, mentionnons les coûts et les difficultés liés à un déplacement, les délais d'attente et le manque de services spécialisés offerts en dehors des grands centres. Fait à souligner, $80 \%$ des participants à cette étude (IC $95 \%$; 64 - $96 \%$ ) ont avoué qu'ils utiliseraient probablement la plate-forme de télémédecine de leur province pour le suivi de leur rendez-vous chez un neurologue. Ces participants ont aussi signalé leur volonté d'utiliser la télémédecine afin de réduire leurs déplacements et d'améliorer leur accès à des soins spécialisés.

Keywords: Parkinson's disease, Rural health, Telehealth

doi:10.1017/cjn.2020.99

Can J Neurol Sci. 2020; 47: 700-704

The medical treatment plan for Parkinson's disease (PD) depends on clinical features which vary from hour to hour throughout the day, vary between patients, and can evolve over time. The complex and highly personalized nature of assessment and treatment planning for PD often involves the input of neurologists with focused interest or specialized training in movement disorders, often at subspecialty movement disorder clinics.

The application of best practices is challenged by limitations in access to healthcare providers including physicians and trained allied health providers with special expertise in PD. Within British Columbia (BC), there are regional discrepancies in access to specialty care for PD which adds to patient and caregiver burden $^{1,2}$ (Figure 1). Telehealth services, which may ease this discrepancy, are increasingly available for clinical use, but the role of these technologies in the complex clinical care of people with PD is not established in Canadian Guidelines for Parkinson Disease. Considering the unique challenges faced by patients with PD in Interior BC, we conducted a mixed-methods needs assessment. A survey was distributed, and a focus group interview was conducted to determine the perceived barriers to healthcare access and views of telehealth applications for management of PD.
Paper and electronic questionnaires were distributed to assess patient perceptions of access to specialist services for management of PD and willingness to use telehealth. A semi-structured focus group interview was also performed to provide qualitative insight. Completed surveys were collected over a 7-month period (June 2018-January 2019). Participants were categorized as travelers (those living $>50 \mathrm{~km}$ from their neurologist) and non-travelers (those who live $\leq 50 \mathrm{~km}$ from their neurologist). Transcript analysis was conducted manually by three researchers (PB, AM, and DP) using thematic analysis. ${ }^{3}$ The anonymized script was analyzed, and themes and subthemes were sorted until consensus was reached by the researchers. Difference in proportion of responses between travelers and non-travelers was investigated for each question using the Fisher's exact test with statistical significance set at $p<0.05$. All quantitative data analyses were conducted using Stata S/E Version $15 .^{4}$

From the Southern Medical Program, University of British Columbia Okanagan, Kelowna, British Columbia, Canada (DP, PB, AM, JS, JY, DW); and Kelowna General Hospital, Kelowna, British Columbia, Canada (DW)

Received April 10, 2020. Final Revisions Submitted May 15, 2020. Date of Acceptance May 18, 2020.

Correspondence to: Dakota Peacock, UBC Campus, 311 Columbia Street, Kamloops, British Columbia, Canada, V2C 2T1. Email: dakota.peacock@alumni.ubc.ca 


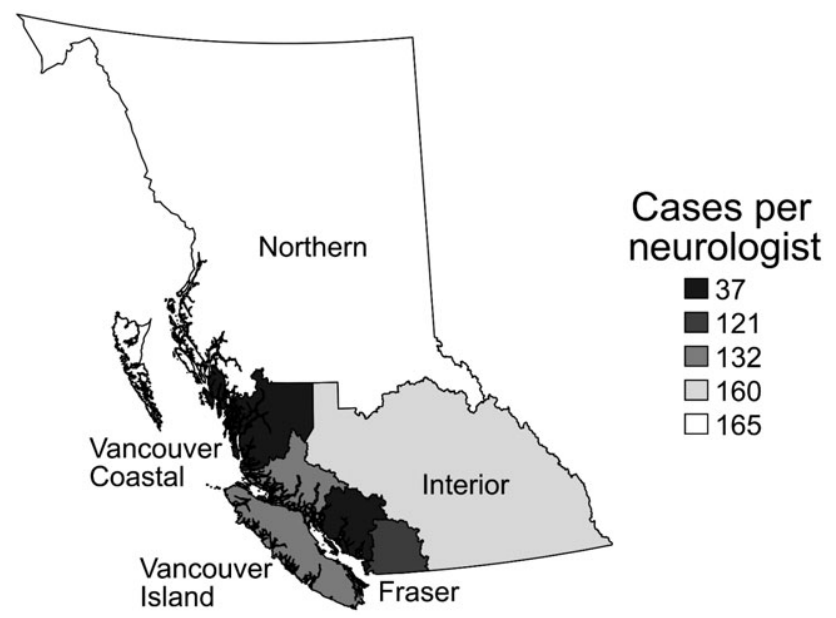

Figure 1: Cases of parkinsonism over 40 years old per neurologist across British Columbian Health Authorities. ${ }^{1,2}$

Participants were not involved in analysis of the script. The study was approved by the Interior Health Research Ethics Board, and the informed consent was obtained for all participants completing the questionnaire or participating in the focus group.

Eighteen surveys were completed (61\% travelers), and seven parties participated in the focus group ( $28 \%$ travelers). The focus group participant characteristics are detailed in Table 1. The average age of focus group participants was 70.9 years old $(\mathrm{SD}=5.9$ years $)$. One of 18 questionnaires was completed online $(6 \%)$.

Questionnaire responses are summarized in Table 2. 52\% (95\% CI 32-72) of participants endorsed a need to live in a larger urban center to get the best care for their PD, and $12 \%$ (95\% CI 025) disagreed with this sentiment. More than two-thirds of travelers and non-travelers report that they never cancel appointments $(p=0.20)$. Travelers were more likely than non-travelers to avoid scheduling clinic appointments in the winter due to travel concerns $(46 \%$ vs. $8 \% ; p<0.01)$.

Most participants (82\%; 95\% CI 64-100) expressed that they would be comfortable using videoconference technology for follow-up appointments with their neurologist. Our participants did not express concern about loss of information in videoconference visits compared to in-office appointments (Table 3).

Thematic analysis of the interview transcript revealed three main clusters: accessibility to quality care, impact of travel, and telehealth (Table 4).

Participants described three topics regarding accessibility to quality care: concern that their family physicians and general neurologists did not have the necessary expertise to manage their $\mathrm{PD}$, an insufficient number of neurologists in their communities and long wait times for initial consultations, and a shortage of expertise in smaller centers and a lack of access to multidisciplinary care and advanced therapies such as deep brain stimulation.

...the rural GPs and or neurologists who are not as familiar with movement disorders, Parkinson's, are less able to assist their patients. (Participant ID 4)

We still have people in our group who are on a waitlist for six months to a year to see a neurologist. They've been diagnosed by their family doctor but to come face-to-face with the neurologist is a long waiting time. (Participant ID 1)

And since ... all sorts of things . . . they could do here. That would be benefit for people with deep brain stimulation. Like replacing these battery packs, you gotta go to Vancouver for minor day surgery. (Participant ID 2)

Impact of travel for medical care was a popular topic at the focus group. Participants discussed the cost of travel, their ability and strategies to attend winter appointments, concerns about driving through poor road conditions, and strain on the patient and family leading to caregiver burnout.

I've chosen to fly as opposed to drive which these days is ... the price of gas is about the same cost. (Participant ID 7)

We have too many hills to go over and I would definitely cancel if the weather turned. (Participant ID 8)

I just feel like I'm letting down my partner because he's the one who needs to see the neurologist, not me. And he can't drive... (Participant ID 8)

Participants discussed their perceptions of the logistics and benefits of potential videoconference appointments with their neurologist. They debated the challenges telehealth may pose for elderly populations less comfortable with videoconference technology as well as proposed accommodations to support them, and they also discussed telehealth scheduling strategies to avoid losing a personal connection with their neurologist. This group perceived three main benefits to implementing a telehealth system in care for PD: the ability to be assessed at home, cost savings, and access to expertise.

I think in every community there's probably an alternative resource that could be accessed [for elderly patients], say the library. ... if they didn't have their own computer at home, then there's probably some place maybe at their local family doctor's office, they could go there for a computer. (Participant ID 7)

I think that [telehealth] would get rid of the white coat syndrome. People get anxious when they see a doctor, and I'm not sure [the doctor] sees the real picture of a person's health. (Participant ID 2)

That might mitigate some of the cost of all this. Both to the system and the patient. (Participant ID 2)

Our sample of people with PD in the Interior Health Region reported limited access to specialty care and services and willingness to use telehealth for follow-up appointments to access specialty care. Our findings suggest that people living with PD in our region are receptive to this approach though this convenience sample is small and was taken from a potentially more outspoken subset of patients and caregivers living with PD.

Participants perceived travel as a barrier to accessing healthcare, a factor known to vary widely in different regions for a variety of conditions. ${ }^{5}$ In our region, winter travel is a particular barrier for travelers which may create seasonal fluctuation in the need for solutions such as telemedicine. Travelers reported 
Table 1: Focus group participant demographics

\begin{tabular}{l|l|c|l|c|c}
\hline Participant ID & \multicolumn{1}{|c|}{ Sex } & Age & Relationship to PD & $\begin{array}{c}\text { Distance from } \\
\text { neurologist }(\mathbf{k m})\end{array}$ & $\begin{array}{c}\text { Number of annual } \\
\text { neurologist visits }\end{array}$ \\
\hline 1 & Female & 72 & Caretaker & 4 & $2-4$ \\
\hline 2 & Male & 68 & Patient & 8 & $2-4$ \\
\hline 3 & Female & 70 & Patient & 8 & $2-4$ \\
\hline 4 & Female & 63 & Patient & 8 & $2-4$ \\
\hline $5^{\text {a }}$ & Male & 83 & Patient & 8 & $<2$ \\
\hline $6^{\text {a }}$ & Female & 67 & Caretaker & 8 & $2-4$ \\
\hline 7 & Female & 74 & Patient & 413 & $<2$ \\
\hline 8 & Female & 70 & Caretaker & 620 & $2-4$ \\
\hline
\end{tabular}

${ }^{\text {a }}$ Participant 6 is the partner and caretaker of 5 .

Table 2: Quantitative analysis of perceived barriers to neurologist access by 18 survey participants and seven focus group participants

\begin{tabular}{|c|c|c|c|c|c|c|c|c|}
\hline \multirow{2}{*}{ Question } & \multirow{2}{*}{ Response } & \multicolumn{2}{|c|}{ Total } & \multicolumn{2}{|c|}{ Travelers } & \multicolumn{2}{|c|}{ Non-travelers } & \multirow{2}{*}{$p$-Value ${ }^{\mathrm{a}}$} \\
\hline & & $n(\%)$ & $95 \% \mathrm{CI}$ & $n(\%)$ & $95 \% \mathrm{CI}$ & $n(\%)$ & $95 \% \mathrm{CI}$ & \\
\hline \multirow{3}{*}{$\begin{array}{l}\text { How often must } \\
\text { you cancel } \\
\text { appointments } \\
\text { with a neurologist } \\
\text { due to travel } \\
\text { concerns? }\end{array}$} & Never & $17(68)$ & $50-86$ & $7(54)$ & $27-81$ & $10(83)$ & $62-100$ & \multirow[t]{3}{*}{0.202} \\
\hline & $\begin{array}{l}\text { Occasional, } \\
\text { sometimes, or } \\
\text { often }\end{array}$ & $8(32)$ & $14-50$ & $6(46)$ & $62-100$ & $2(17)$ & $0-38$ & \\
\hline & Always & 0 & 0 & 0 & 0 & 0 & 0 & \\
\hline \multirow{3}{*}{$\begin{array}{l}\text { Do you avoid } \\
\text { appointments at } \\
\text { certain times of } \\
\text { the year due to } \\
\text { travel concerns? }\end{array}$} & Never & $10(40)$ & $21-59$ & $1(8)$ & $0-22$ & $9(75)$ & $50-100$ & \multirow[t]{3}{*}{$0.0025 *$} \\
\hline & $\begin{array}{l}\text { Occasional, } \\
\text { sometimes, or } \\
\text { often }\end{array}$ & $8(32)$ & $14-50$ & $6(46)$ & $19-73$ & $2(17)$ & $0-38$ & \\
\hline & Always & $7(28)$ & $10-46$ & $6(46)$ & $19-73$ & $1(8)$ & $0-24$ & \\
\hline \multirow{3}{*}{$\begin{array}{l}\text { To get the best } \\
\text { care for my PD, I } \\
\text { need to live in a } \\
\text { larger urban } \\
\text { center }\end{array}$} & $\begin{array}{l}\text { Disagree or } \\
\text { strongly disagree }\end{array}$ & $3(12)$ & $0-25$ & $1(8)$ & $0-22$ & $2(17)$ & $0-38$ & \multirow[t]{3}{*}{1} \\
\hline & $\begin{array}{l}\text { Neither agree nor } \\
\text { disagree }\end{array}$ & $9(36)$ & $17-55$ & $5(38)$ & $12-65$ & $4(33)$ & $7-60$ & \\
\hline & $\begin{array}{l}\text { Agree or strongly } \\
\text { agree }\end{array}$ & $13(52)$ & $32-72$ & $7(54)$ & $27-81$ & $6(50)$ & $22-78$ & \\
\hline
\end{tabular}

${ }^{\mathrm{a}} p$ values calculated for the difference between travelers and non-travelers.

*Statistical significance $(p<0.05)$.

personal, family, and financial strain consistent with studies in chronic disease where travel is associated with poor treatment adherence, increased cost, and higher rates of absenteeism. ${ }^{6}$ Patients perceive that living in larger urban centers results in greater quality of care including multidisciplinary care and advanced therapies such as deep brain stimulation.

Participants were enthusiastic regarding telehealth improving access to care. However, there are knowledge gaps in applying telemedicine to the varied clinical needs of PD patients (e.g., assessments for tremor, dyskinesia, dystonia, rigidity, or gait difficulty). Tone is not easily assessed remotely, and most approaches to this limitation employ clinical personnel at the patient end of communication. Barbour et al. (2016) studied a cohort of patients with PD over a 3-year period of telemedicine care assisted by specially trained local nurses performing the
Unified Parkinson's Disease Rating Scale (UPDRS) Part 3. ${ }^{7}$ This study demonstrated that such a system could be used in provision of care remotely, though no control group was studied and this system would require additional skilled personnel who are then another limited resource. Dorsey et al. (2013) published a small randomized controlled trial of telemedicine for PD management with the telemedicine group undergoing a modified UPDRS exam in which rigidity and postural stability were not assessed. ${ }^{8}$ In this study, in the absence of these elements of the usual exam, the telemedicine group showed outcomes comparable to the usual care group as measured by the 39-Item Parkinson's Disease Questionnaire and the modified UPDRS score.

Effective use of telemedicine as part of a system of care for PD must incorporate an understanding of the patient's clinical needs and what aspects of the examination are essential to meet those 
Table 3: Quantitative analysis of telehealth perceptions by 18 survey participants

\begin{tabular}{|c|c|c|c|c|c|c|c|c|}
\hline \multirow{2}{*}{ Question } & \multirow{2}{*}{ Response } & \multicolumn{2}{|c|}{ Total } & \multicolumn{2}{|c|}{ Travelers } & \multicolumn{2}{|c|}{ Non-travelers } & \multirow{2}{*}{$p$-Value ${ }^{\mathrm{a}}$} \\
\hline & & $n(\%)$ & $95 \% \mathrm{CI}$ & $n(\%)$ & $95 \% \mathrm{CI}$ & $n(\%)$ & $95 \% \mathrm{CI}$ & \\
\hline \multirow{3}{*}{$\begin{array}{l}\text { I would be comfortable using } \\
\text { videoconference technology for follow- } \\
\text { up appointments with my neurologist }\end{array}$} & Disagree or strongly disagree & $1(6)$ & $0-17$ & 0 & 0 & 1 (14) & $0-40$ & \multirow[t]{3}{*}{0.691} \\
\hline & Neither agree nor disagree & $2(12)$ & $0-27$ & $1(10)$ & $0-29$ & $1(14)$ & $0-40$ & \\
\hline & Agree or strongly agree & $14(82)$ & $64-100$ & $9(90)$ & $71-100$ & $5(71)$ & $38-100$ & \\
\hline \multirow{3}{*}{$\begin{array}{l}\text { I think important information would be } \\
\text { lost by using videoconference } \\
\text { technology for follow-up appointments } \\
\text { with my neurologist instead of in-office } \\
\text { appointments }\end{array}$} & Disagree or strongly disagree & $4(22)$ & $3-41$ & $2(18)$ & $0-41$ & $2(28)$ & $0-62$ & \multirow[t]{3}{*}{0.569} \\
\hline & Neither agree nor disagree & $8(44)$ & $21-67$ & $6(55)$ & $25-84$ & $2(28)$ & $0-62$ & \\
\hline & Agree or strongly agree & $6(33)$ & $12-55$ & $3(27)$ & $1-64$ & $3(42)$ & $6-80$ & \\
\hline \multirow{3}{*}{$\begin{array}{l}\text { If your Parkinson treatment were proven } \\
\text { to be as good, how likely would you be } \\
\text { to use videoconference technology for } \\
\text { follow-up appointments with your } \\
\text { neurologist instead of in-office } \\
\text { appointments? }\end{array}$} & Unlikely of very unlikely & $2(8)$ & $0-19$ & $1(8)$ & $0-22$ & $1(8)$ & $0-24$ & \multirow[t]{3}{*}{0.787} \\
\hline & Undecided & $3(12)$ & $0-25$ & $1(8)$ & $0-22$ & $2(17)$ & $0-38$ & \\
\hline & Likely or very unlikely & $20(80)$ & $64-96$ & $11(85)$ & $65-100$ & 9 (75) & $50-100$ & \\
\hline
\end{tabular}

Data from seven focus group participants have been pooled with survey participant data regarding likelihood to use videoconference technology if it were proven as good as in-office appointments.

${ }^{\mathrm{a}} p$-Values calculated for the difference between travelers and non-travelers. 


\section{Table 4: Clusters, themes, and subthemes created from interview analysis}

\begin{tabular}{|c|c|}
\hline Cluster & Themes \\
\hline \multirow{6}{*}{$\begin{array}{l}\text { 1. Accessibility to } \\
\text { quality care }\end{array}$} & 1.1 Availability of nearby expertise \\
\hline & 1.2 Timely access to specialist care \\
\hline & 1.3 Differences based on the size of municipality \\
\hline & A. Access to specialists \\
\hline & B. Access to multidisciplinary healthcare teams \\
\hline & C. Access to deep brain stimulation \\
\hline \multirow[t]{3}{*}{ 2. Impact of travel } & 2.1 Cost \\
\hline & 2.2 Ability to attend appointments \\
\hline & 2.3 Strain on patient and family \\
\hline \multirow[t]{7}{*}{ 3. Telehealth } & $\begin{array}{l}\text { 3.1 Perceptions of feasibility of telehealth use in elderly } \\
\text { populations }\end{array}$ \\
\hline & $\begin{array}{l}3.2 \text { Proposed accommodations for use of telehealth in } \\
\text { elderly populations }\end{array}$ \\
\hline & 3.3 Proposed scheduling of telehealth \\
\hline & 3.4 Perceived advantages of telehealth \\
\hline & A. Assessments at home \\
\hline & B. Economic benefits \\
\hline & C. Improved quality of care \\
\hline
\end{tabular}

needs. For instance, the value of tone as a clinical feature is greater in the initial consultation and in certain phenotypic subgroups (e.g., akinetic-rigid or postural instability and gait disturbance Parkinsonism vs. tremor-dominant PD). We expect that the suitability of telehealth for care of PD patients is not even across these scenarios. Some aspects of the exam may be less critical in the follow-up if a clinician familiar with the patient can interpret visual information while drawing on observations from a previous face-to-face exam. Appropriate selection of patients and consideration of the reason for an encounter are therefore essential for a clinician to be comfortable in making management decisions via telehealth. Similar surveys have shown high rates of willingness from patients with PD to use internet-based video communication for participation in clinical research, ${ }^{9}$ but a viable solution must be easy for the patient. In our region, telehealth services launched for general medical use in 2003 for management of thoracic surgery patients. ${ }^{10}$ Telehealth services are now provided in 40 regional hospitals and healthcare centers in the Interior Health Region, and these community sites can serve as a nearby point of access with a consistent system that does not require the patient to have special technical expertise. There may be a role for mixed models in which patients can access some care from home, with appropriate support and training from community supports, or home health monitoring.

The quantitative and qualitative data were gathered from a small self-selected sample which may be affected by sampling bias and may not be generalizable to populations in other regions of Canada. The response rate of our survey is not estimable as we do not know the total number of unreturned surveys. Sampling bias was mitigated by surveying the population in both winter and summer months, and nonresponse bias was mitigated by collaborating with community support groups and local neurologist offices. The outcome of these methods are consistent with previous investigations of patient perceptions of telehealth. ${ }^{11,12}$

People living with PD in Interior Health Region perceive limited access compared with those living in larger urban centers citing less access to specialist care, specialty services, and strain related to travel. Most participants expressed an interest in applying telehealth for management of PD.

\section{CONFLICT OF INTEREST}

DP reports grants from Parkinson's Foundation during the conduct of the study. The remaining authors report not conflicts of interest.

\section{Statement of Authorship}

DP and DW conceived and designed the study. All authors contributed to the analysis or interpretation of data, and critical revision with intellectual content. All authors approve of the submitted manuscript.

\section{REFERENCES}

1. BC Centre for Disease Control. Chronic disease dashboard. [cited 2019 Jan 17]. Available at: www.bccdc.ca/health-professionals/ data-reports/chronic-disease-dashboard

2. BC College of Physicians and Surgeons. Physician directory. [cited 2019 Jan 20]. Available at: www.cpsbc.ca/physician_search

3. Lacey A, Luff D. Trent focus for research and development in primary health care: an introduction to qualitative data analysis. Nottingham, UK: Trent Focus Group, 2001.

4. StataCorp. Stata statistical software: release 15. College Station, TX: StataCorp LP; 2017.

5. Syed ST, Gerber BS, Sharp LK. Traveling towards disease: Transportation barriers to health care access. J Community Health. 2013;38:976-93.

6. Buzza C, Ono SS, Turvey C, et al. Distance is relative: Unpacking a principal barrier in rural healthcare. $J$ Gen Intern Med. 2011;26(2):648-54.

7. Barbour PJ, Arroyo J, High S, et al. Telehealth for patients with Parkinson's disease: delivering efficient and sustainable longterm care. Hospital Pract. 2016;44(2):92-97.

8. Dorsey ER, Venkataraman V, Grana MJ, et al. Randomized controlled clinical trial of "Virtual house calls" for Parkinson disease. JAMA Neurol. 2013;70(5):565-70.

9. Shprecher D, Noyes K, Biglan K, et al. Willingness of Parkinson's disease patients to participate in research using internet-based technology. Telemed J E Health. 2012;18(9):684-7.

10. Humer MF, Campling BG. The role of telemedicine in providing thoracic oncology care to remote areas of British Columbia. Curr Oncol Rep. 2017;19(52):1-7.

11. Thurmond V, Boyle DK. An integrative review of patients' perceptions regarding telehealth used in their health care. Online J Knowl Synth Nurs. 2002;9(2):12-32.

12. Finkelstein S, Speedie S, Demiris G, Veen M, Lundgren J, Potthoff S. Telehomecare: quality, perception, satisfaction. Telemed J EHealth. 2004;10(2):122-8. 